\title{
Spirometry in healthy men: a correlation with smoking and with mild symptoms
}

\author{
F. PRIETO ${ }^{1}$, M. J. ENGLISH, G. M. COCHRANE, T. J. H. CLARK, AND \\ B. G. RIGDEN
}

From the Graduate Division of Biomedical Engineering, University of Sussex, and Guy's Hospital, London SE1 9RT, UK

Prieto, F., English, M. J., Cochrane, G. M., Clark, T. J. H., and Rigden, B. G. (1978). Thorax, 33, 322-327. Spirometry in healthy men: a correlation with smoking and with mild symptoms. Symptoms, smoking history, and variates taken from the forced expiratory manoeuvre were studied in a group of 271 healthy men attending a mass radiography unit. It was found that correlation of the forced expiratory ratio $\left(\mathrm{FEV}_{1} / \mathrm{FVC}\right)$ with the presence of mild or moderate respiratory symptoms was at least as satisfactory as that of technically more complicated measurements such as $\mathrm{MEF}_{50}$ and $\mathrm{MEF}_{75}$. In asymptomatic individuals those differences associated with smoking were the same for $\mathrm{FEV}_{1} / \mathrm{FVC}$ as for $\mathrm{MEF}_{75}$. Asymptomatic abnormalities of lung function were not observed. Simple measurements such as $\mathrm{FEV}_{1} / \mathrm{FVC}$ can therefore provide as much information from a forced expiratory manoeuvre to screen for early airways obstruction as $\mathrm{MEF}_{50}$ and $\mathrm{MEF}_{75}$.

Lung function tests have proved valuable as diagnostic or prognostic guidelines, both in clinical practice and in occupational medicine. It is recognised, however, that their correlation with severity of lung disease is not perfect and that their usefulness is limited because of the wide range of factors that influence them (Shephard and Turner, 1959). In recent years there has been renewed interest in the application of lung function tests in preventive medicine, particularly in relation to chronic airways obstruction (Bates, 1973).

The forced expiratory spirogram has long been known to reflect changes in airway patency associated with emphysema (Raither, 1912), and ways for measuring and assessing the forced expiratory spirogram have been in use for over 20 years (Tiffeneau and Pinelli, 1948; Tiffeneau et al., 1949; Gaensler, 1951; Leuallen and Fowler, 1955). More recently, after the discovery (Dayman, 1951) and clarification (Hyatt et al., 1958; Fry and Hyatt, 1960) of the peculiar relationship between air flow, lung volume, and transpulmonary pressure during forced expiration, measurement of instantaneous flow over the last half of the vital capacity during a forced expiratory manoeuvre has been proposed as a means of detecting obstruction in small airways (McFadden

${ }^{1}$ Present address: Hospital Espanol, Ejercito Nacional 613, Mexico 5, DF. and Linden, 1972). The contribution of small airways to total airways resistance is greater at lungo volumes below $50 \%$ of vital capacity than at larger volumes (Macklem and Mead, 1967).

Simple measurements, even if not restricted to the second half of the expiratory vital capacity, might be useful in discovering individuals at special risk of developing progressive airways obstruction. Adoption of such indices, however, in 3 preference to the more sophisticated flow-rateo measurements for detecting preclinical disease 3 must be based, in addition to practical considerations, on an assessment of their relative sensitivities to the effects of factors such as smoking and the presence of mild respiratory symptoms.

We present the results of the study of a group of apparently healthy men attending a mass radiography unit. The effect of mild or moderates respiratory symptoms on different variates derived ${ }^{\omega}$ from the forced expiratory manoeuvre were analysed for the complete group, while differences? associated with smoking were studied only fore those who were asymptomatic.

\section{Methods}

A sample of about one-fifth of those men attend $\stackrel{\mathbb{D}}{\varrho}$ ing a mass radiography unit at Brighton was obtained during regular sessions over a period of 
six months (spring and summer 1975). The subjects included about equal numbers of patients referred by general practitioners to rule out chest disease and employees or students required to submit themselves to routine miniature chest radiography. For practical reasons the sampling was not random but systematic, every fifth person being invited to take part in a 'research project about lung function tests'. There were few refusals.

Traces of flow and volume against time were made on a multi-channel ink-jet recorder (Mingograph 34T) from signals produced by a commercially available desktop spirometer (Monaghan 403 pulmonary function analyser), which was carefully calibrated for volume against a dry spirometer (Ohio 840) and for flow against calibrated 'Rotameters' using air at $33^{\circ} \mathrm{C}$ saturated with water vapour; volume and flow were recorded at BTPS. At least three sets of traces were obtained after one to three 'practice blows' during which the subject was instructed in the correct technique. The manoeuvre was performed with the subject in the standing position and not using a nose-clip. Traces corresponding to the largest FVC for each subject were used for analysis. The whole procedure was supervised by one or other of two trained personnel. After the test each subject answered the Medical Research Council's questionnaire (1960) to provide information about respiratory symptoms. Questions were added to bring into the investigation the effect of any recent respiratory infections.

The following measurements were obtained from the traces: FVC, FEV $_{1}, F_{1} V_{1} / F V C$, PFR (the maximum instantaneous flow achieved), instantaneous flow at $50 \%$ of expired vital capacity $\left(\mathrm{MEF}_{50}\right)$, instantaneous flow at $75 \%$ of expired vital capacity $\left(\mathrm{MEF}_{75}\right)-100 \%$ being residual volume-and forced expiratory time (FET). Zero time for FEV $_{1}$ and for FET was obtained by backward extrapolation of the steepest slope of the volume-time curve to the baseline (Dayman, 1967).

The statistical approach consisted of converting the questionnaire answers into scores for each of five symptoms: cough and expectoration, prolonged periods of productive cough, acute respiratory illness, wheeze, and dyspnoea (see Appendix). We then calculated the correlation of these three ordinal and two dichotomous variables taken together with each of the seven measurements of the forced expiratory manoeuvre, after allowing for the effect of age. The square of this multiplepartial correlation coefficient gives the proportion of the variability of each measurement explained by the five symptom scores (Blalock, 1972) and hence indicates their relative sensitivities. This analysis was carried out on the subgroup formed by men without productive cough 'on most days or nights for more than two months for the past three years or more', without a previous diagnosis of asthma or emphysema, and without radiological signs of emphysema (Simon, 1971) as judged from a $100 \mathrm{~mm}$ film viewed under optical magnification by an experienced physician. A similar analysis was carried out in respect of smoking among strictly symptom-free individuals (no cough or expectoration, no history of acute chest illness in the past three years, no wheeze, no dyspnoea on effort, and no acute respiratory tract infection in the past three months). Two dummy variables were used to contain information about smoking, the first assuming value one for smokers and zero for non-smokers and ex-smokers, the second assuming value one for smokers or ex-smokers and zero for non-smokers: the multiple partial correlation of these two variables with each measurement of the forced expiratory manoeuvre was calculated allowing for the effect of age.

\section{Results}

A total of 271 men met the requirements of the study. Of these, 45 were entirely symptom free. The ages of all subjects ranged from 16 to 79 years (mean 40.8 , SD 16.6). There were $62 \%$ smokers, $17 \%$ ex-smokers, and $21 \%$ non-smokers: Lifetime cigarette consumption among smokers and ex-smokers ranged from $1 / 20$ to 106 packyears* (median 13.3, mean 18.7), 80\% having smoked less than 30 pack-years. Among the asymptomatic subgroup, age ranged from 16 to 75 years (mean 39.0, SD 15.8), and there were 20 smokers and 9 ex-smokers with a lifetime cigarette consumption of $1 / 20$ to 50 pack-years (median 10.0), 25 subjects having smoked less than 30 pack-years.

The variability of each variate can be regarded as the sum of effects due to age, height (or body size), unknown factors, and the factors under investigation-such as respiratory symptoms or smoking.

The variability of each variate explained by the symptom scores and expressed as a percentage of the variance unexplained by age is given in Table 1. This percentage quantifies the magnitude of one or several symptoms after allowing for age differences. Comparison can be made between this and the percentage of variability explained by

*A pack-year is defined as the smoking of 7300 cigarettes, the equivalent of 20 cigarettes a day for one year. 
age alone. The residual variability is unexplained by either age or symptoms and is partially accounted for by the variability of the individual subject and equipment (Cochrane et al., 1977). Mean and standard error of the mean values are shown for each variate in asymptomatic patients in Table 2.

Table 1 Forced expiratory measurements and respiratory symptoms in 271 men

\begin{tabular}{lll}
\hline $\begin{array}{l}\text { Dependent } \\
\text { variable }\end{array}$ & $\begin{array}{l}\text { Percentage of total } \\
\text { variance explained } \\
\text { by age } \dagger\end{array}$ & $\begin{array}{l}\text { Percentage of variance } \\
\text { (unexplained by age) } \\
\text { explained by symptom } \\
\text { scores }\end{array}$ \\
\hline FEV $_{1 / \text { FVC }}$ & $18 \cdot 1$ & $4 \cdot 32$ \\
MEF $_{7 s^{*}}$ & $53 \cdot 1$ & $3 \cdot 97$ \\
FEV $_{1}$ & $49 \cdot 6$ & $3 \cdot 16$ \\
MEF $_{\text {so }}$ & $30 \cdot 6$ & $3 \cdot 14$ \\
FVC & $44 \cdot 2$ & $2 \cdot 16$ \\
FET & 32.9 & $1 \cdot 42$ \\
PFR & $17 \cdot 0$ & $1 \cdot 27$ \\
\hline
\end{tabular}

${ }^{*}$ MEF $_{75}$ was expressed as the square root of observed value and FET as logarithm of observed value to correct for positive skewness of frequency distribution shown by graphical analysis (no other test for normality was applied).

$\dagger$ These percentages assume rectilinear regression on age; vital capacity does not begin to decrease until after age of 35 (Hutchinson, 1846) and regression of PFR on age (Gregg and Nunn, 1973) has been shown to be curvilinear-ascending up to age of 30 years or so and descending therefrom. Consequently, figure given here probably underestimates proportion of variance explained by age.

Table 2 Symptoms and spirometric measurements. Mean value with standard error of mean in parentheses

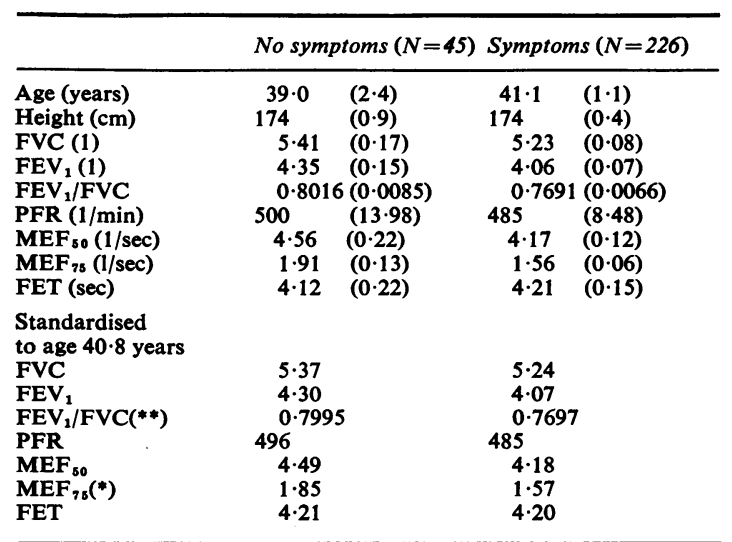

$(* *) \mathrm{P}<0.01$ (Student's ' $t$ ' test on age-standardised data).

$\left(^{*}\right) \quad P<0.05$ (Student's ' $t$ ' test on age-standardised data).

The sensitivity of each measurement to effects associated with symptoms is directly proportional to the percentage of its variance explained by them. Although only a small proportion of the variance of any of the seven variates analysed here was connected with mild or moderate symp- toms as represented by the arbitrary scores that $\stackrel{\vec{F}}{\stackrel{\vec{S}}{+}}$ were used, comparison between them showed that $\bar{C}$ the proportion was nearly the same for $\mathrm{FEV}_{1} / \mathrm{FVC}$ 을 and $\mathrm{MEF}_{75}$ and for $\mathrm{FEV}_{1}$ and $\mathrm{MEF}_{50}$, all being in $\frac{\bar{s}}{\overrightarrow{9}}$ the region of $3 \cdot 1$ to $4 \cdot 3 \%$. FVC, FET, and PFR $\stackrel{\square}{\Omega}$ appeared to be less sensitive.

In the asymptomatic subgroup a definite association between smoking and forced expiratory measurements was found. The strength of this $\vec{\omega}$

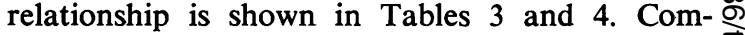
parison of the sensitivities of the different variates $\vec{x}$

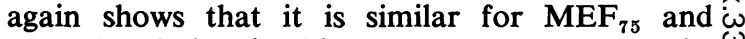
$\mathrm{FEV}_{1} / \mathrm{FVC}$, but in this case PFR appeared to be $\hat{\omega}$ nearly as sensitive as $\mathrm{FEV}_{1}$, while $\mathrm{MEF}_{50}$ cor- $\dot{\omega}$ related less well and FET hardly at all with smok- $N$ ing. Analysis of differences explained by smoking 음 was confined to asymptomatic subjects to exclude any interacting or disturbing effects of symptoms, $\subseteq$ however mild they might have been. A similar analysis including probands with symptoms (the $\vec{\theta}$ results of which are not presented here) gave the same relative results for the different measurements but a lesser proportion of their variances was explained by smoking - probably reflecting the presence of influences unaccounted for, but independent of smoking, that were absent or minimal in the asymptomatic subgroup.

Of the 45 asymptomatic subjects, none was $\overrightarrow{\overrightarrow{0}}$ found to have values outside presently accepted $\frac{3}{3}$ normal range, emphasising the difficulty of detecting early disease based solely on forced expiratory measurements.

Table 3 Forced expiratory measurements and the smoking habit in 45 asymptomatic men

\begin{tabular}{lll}
\hline Dependent & $\begin{array}{l}\text { Percentage of total } \\
\text { variance explained } \\
\text { by age }\end{array}$ & $\begin{array}{l}\text { Percentage of variance } \\
\text { (unexplained by age) } \\
\text { explained by smoking }\end{array}$ \\
\hline MEF $_{75}$ & $48 \cdot 6$ & $13 \cdot 7$ \\
FEV $_{1} /$ FVC & $12 \cdot 6$ & $12 \cdot 5$ \\
FEV $_{1}$ & $49 \cdot 2$ & 11.9 \\
PFR $_{\text {MEF }}$ & $30 \cdot 2$ & $11 \cdot 3$ \\
FVC $_{50}$ & $22 \cdot 1$ & $8 \cdot 7$ \\
FET $^{*}$ & $44 \cdot 7$ & $4 \cdot 1$ \\
\end{tabular}

${ }^{*} \mathrm{MEF}_{75}$ was expressed as square root of observed value and FET as $\omega$ logarithm of observed value to preserve uniformity with previous analysis (cf. note under Table 1).

\section{Discussion}

A larger percentage deviation from predicted values has been found among smokers for measure- $\stackrel{\mathbb{\Omega}}{\Omega}$ ments such as $\mathrm{MEF}_{75}, \mathrm{FET}$, or closing volume than $\mathbb{D}$ for $\mathrm{FEV}_{1}$, or $\mathrm{FEV}_{1} / \mathrm{FVC}$ (Cochrane et al., 1974). Similarly, a greater deviation below the predicted values for the maximal mid-expiratory flow rate 8 
Table 4 Smoking and spirometric measurements among 45 asymptomatic men

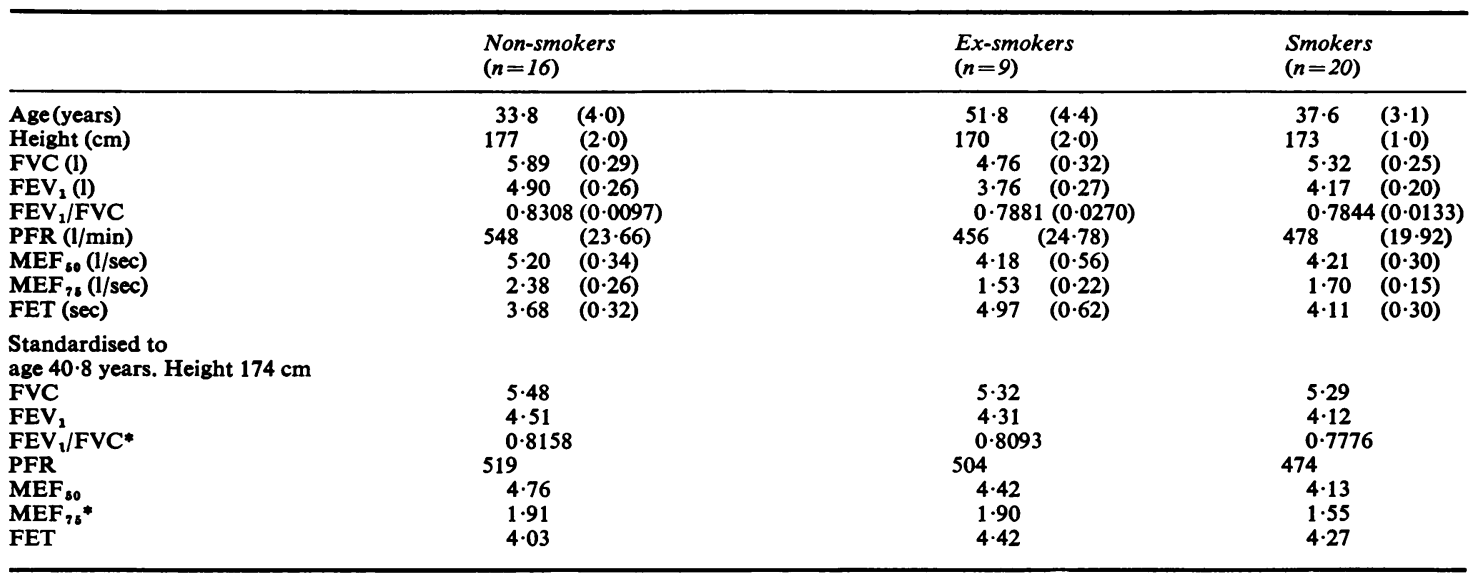

*P $\mathrm{P} 0.05$ (Student's ' $t$ ' test on age- and height-standardised data, non-smokers, and ex-smokers compared to smokers).

Note: No significant difference found between groups where three group analysis of variance ( $F$ test) was used.

(MMEFR) as compared with $\mathrm{FEV}_{1}$ has been shown in some patients with chronic bronchitis and frequency-dependent dynamic compliance (McFadden and Linden, 1972). However, judging the change of a measurement without reference to the variability of the test in normal people is potentially misleading (McCarthy et al., 1975) since a small change in a very reproducible index may be as significant as a greater change in a more variable one, as exemplified by the work of Fairbairn et al. (1962). Comparing peak flow and spirometric measurements, they showed that even though the difference between the mean values observed in a group of bronchitic patients and in a healthy group was greater for MMEFR, the best discriminatory power corresponded to $\mathrm{FEV}_{1}$.

There is no indication that instantaneous flowrate measurements are more sensitive than $\mathrm{FEV}_{1}$ or $\mathrm{FEV}_{1} / \mathrm{FVC}$ when compared either with symptoms (Higgins and Keller, 1973) or with smoking. In consequence, practical and financial considerations may be allowed more importance when the selection of measurements for practical use is under discussion. So far research has included comparison of asymptomatic groups of subjects with groups in whom symptoms would warrant a clinical diagnosis of airways obstruction. The present work shows that in some people symptoms may be noticed before it becomes possible to demonstrate significant changes in terminal airflow, and this challenges the supposition that a prolonged period of asymptomatic decline in lung function may occur, thus prompting the need for tests of this early change in ventilatory capacity.
Our main purpose, however, is to exclude symptomatic subjects from analysis and to draw some inferences as to the relative value of spirometric indices in the preclinical stages of disease.

The results suggest that sufficient measurements can be made from a forced expiratory spirogram to identify a potential risk group, but this requires much better normal data for variates such as MMEFR. Our results also show that there is little to be gained in practice by making technically more complicated measurements of instantaneous flow-rate. This is probably best explained by the uniformity of factors determining maximum expiratory flow over most of the manoeuvre, while the better reproducibility of averaging indices such as $\mathrm{FEV}_{1}$ stems from the smoothing out of variations occurring at instantaneous points. The ratio of $\mathrm{FEV}_{1}$ to the FVC is so closely related to the average time-constant of the system during the first half to three-quarters of the manoeuvre (Miller et al., 1959; Dayman, 1961; Sobol et al., 1973) that it is a good summary measure, and the same may be said of MMEFR though this measurement, regrettably, is less reproducible. A forced expiratory spirogram is probably all that is needed at present to assess forced expiration in clinical and epidemiological practice. Comparison of the results against suitable standards obtained from sufficiently large and representative groups of non-smokers may usefully be applied when examining smokers or people with symptoms in the attempt to discover those with early airflow limitation and then to subject them to special preventative counselling measures. 
F. Prieto was supported by a scholarship from Beca General de Division Abelardo L. Rodruiguez Mexico City, Mexico. We most gratefully acknowledge the suggestion by Professor J. F. Scott of La Trobe University that we should use the multiple-partial correlation coefficient. This work was greatly helped by the efficient collaboration of Mrs. Susan Whiting, respiratory physiology technician.

\section{Appendix}

SYMPTOM SCORES USED IN THIS STUDY

\section{Cough and expectoration}

No cough or expectoration

Cough or phlegm only on getting up (not on most days)

Cough or phlegm during the day or at night (not on most days)

Usual cough but no phlegm

Usual cough and phlegm

\section{Periods of productive cough}

None lasting as long as three weeks

One or more lasting as long as three weeks but never more than two months for two consecutive years

\section{Score}

0

1

2

\section{Acute respiratory illnesses}

No history of chest illnesses during past three years and no acute respiratory infection within past three months

No history of chest illnesses during past three years. A cold within past three months, not affecting chest

No history of chest illnesses. Cold plus dry cough or chest pain within last three months

No history of chest illnesses except for a cold with productive cough within past three months

History of chest illnesses keeping him/her from normal activities for one week or more. No cold within past three months

History of chest illnesses (as in 4) plus a cold without productive cough within the past three months

History of chest illnesses and cold with productive cough within the past three months

\section{Dyspnoea on effort}

Able to keep up with people of the same age walking on level ground

Unable to do so because of dyspnoea

Wheeze

Never hear wheezing or whistling sounds in their chest

Have heard such sounds but not on most days or nights for any period and have not had attacks of breathlessness and wheeze
Have had more or less ill-defined attacks of shortness of breath with wheezing (not known asthmatics)

Hear wheezing sounds from chest on most days or nights (not known asthmatics)

Score

\section{References}

Bates, D. V. (1973). The fate of the chronic bronchitic; a report of the ten year follow-up in the Canadian Department of Veterans' Affairs coordinated study of chronic bronchitis. American Review of Respiratory Disease, 108, 1043-1065.

Blalock, H. M. (1972). Social Statistics, 2nd edition, chapter 19, pp. 458-459. McGraw-Hill Book Company, New York.

Cochrane, G. M., Prieto, F., and Clark, T. J. H. (1977). Intrasubject variability of maximal expiratory flow volume curve. Thorax, 32, 171-176.

Cochrane, G. M., Prieto, F., Hickey, B., Benatar, S. R., and Clark, T. J. H. (1974). Early diagnosis of airways obstruction. Thorax, 29, 389-393.

Dayman, H. (1951). Mechanics of airflow in health and in emphysema. Journal of Clinical Investigation, 30, 1175-1190.

Dayman, H. (1961). The expiratory spirogram. American Review of Respiratory Disease, 83, 842-855.

Dayman, H. (1967). The forced expiratory spirogram; technique. In Proceedings of the Tenth Aspen Emphysema Conference, pp. 443-447. U.S. Department of Health Education and Welfare. Washington Government Printing Office.

Fairbairn, A. S., Fletcher, C. M., Tinker, C. M., and Wood, C. H. (1962). A comparison of spirometric and peak expiratory flow measurements in men with and without chronic bronchitis. Thorax, 17, 168-174.

Fry, D. L., and Hyatt, R. E. (1960). Pulmonary mechanics: A unified analysis of the relationship between pressure, volume, and gas flow in the lungs of normal and diseased subjects. American Journal of Medicine, 29, 672-689.

Gaensler, E. A. (1951). Analysis of the ventilatory defect by timed capacity measurements. American Review of Tuberculosis, 64, 256-278.

Gregg, I., and Nunn, A. J. (1973). Peak expiratory flow in normal subjects. British Medical Journal, 3, 282-284.

Higgins, M. W., and Keller, J. B. (1973). Seven measures of ventilatory lung function. American Review of Respiratory Disease, 108, 258-272.

Hutchinson, J. (1846). On the capacity of the lungs, and on the respiratory movements, with the view of establishing a precise and easy method of detecting disease by the spirometer. Lancet, 1, 630-632.

Hyatt, R. E., Shilder, D. P., and Fry, D. L. (1958). Relationship between maximum expiratory flow and degree of lung inflation. Journal of Applied Physiology, 13, 331-336.

Leuallen, E. C., and Fowler, W. S. (1955). Maximum mid-expiratory flow. American Review of Tuberculosis, 72, 783-800. 
Macklem, P. T., and Mead, J. (1967). Resistance of central and peripheral airways measured by a retrograde catheter. Journal of Applied Physiology, 22, 395-401.

McCarthy, D. S., Craig, D. B., and Cherniack, R. M. (1975). Intraindividual variability in maximal expiratory flow-volume and closing volume in asymptomatic subjects. American Review of Respiratory Disease, 112, 407-411.

McFadden, E. R., Jun., and Linden, D. A. (1972). A reduction in maximum mid-expiratory flow rate. A spirographic manifestation of small airway disease. American Journal of Medicine, 52, 725-737.

Medical Research Council's Committee on the Aetiology of Chronic Bronchitis (1960). Standardised questionaries on respiratory symptoms. British Medical Journal, 2, 1665.

Miller, W. F., Johnson, R. L., and Wu, N. (1959). Relationships between fast vital capacity and various timed expiratory capacities. Journal of Applied Physiology, 14, 157-163.

Raither, E. (1912). Studien über Emphysem. Beiträge zur Klinik der Tuberculose und Spezifischen Tuberkuloseforschung. 22, 137-164.
Shephard, R. J., and Turner, M. E. (1959). On the probability of correct diagnosis by pulmonary function tests. Thorax, 14, 300-304.

Simon, G. (1971). Principles of Chest X-ray Diagnosis, 3rd edition, pp. 151-155. Butterworths, London.

Sobol, B. J., Park, S. S., and Emirgil, C. (1973). Relative values of various spirometric tests in the early detection of chronic obstructive pulmonary disease. American Review of Respiratory Disease, 107, 753-762.

Tiffeneau, R., Bousser, J. and Drutel, P. (1949). Capacité vitale et capacité pulmonaire utilisable a l'effort. Critères statique et dynamique de la ventilation pulmonaire. Paris Médical, 39, 543-546.

Tiffeneau, R., and Pinelli, A. (1948). Régulation bronchique de la ventilation pulmonaire. Journal Francais de Médicine et Chirurgie Thoraciques, 2, 221-244.

Requests for reprints to: Professor T. J. H. Clark, Guy's Hospital, London SE1 9RT. 